ISSN 2455-2550

DOI: http://dx.doi.org/10.20431/2455-2550.0201002

www.arcjournals.org

\title{
Studies to See the Effect of Nutrition on the Health Status of Selected Retired and Active Working Elderly People
}

\author{
Sangita Sood $^{1}$, Shalini Bharmoria ${ }^{2}$ \\ ${ }^{1}$ Professor, Department of Food Science and Nutrition, CSK HPAU, Palampur, \\ Himachal Pradesh, India, \\ sangitasood@rediffmail.com \\ ${ }^{2}$ M.Sc. Scholar, Department of Food Science and Nutrition, CSK HPAU, Palampur, \\ Himachal Pradesh, India,
}

\begin{abstract}
In the present study an effort was made to assess the nutritional status of 120 elderly residents of Baijnath and Panchrukhi blocks of District Kangra. From the collected information it was observed that 44.17 per cent of subjects had Grade I and Grade II obesity. Energy, carbohydrate and fat intake was higher as compare to recommended dietary allowances and found to be positively correlated with anthropometric parameters. Age had significant and negative association with anthropometric parameters namely Body Mass Index (BMI) (-0.343**), Arm Muscle Circumference (AMC) (-0.284**), Arm Muscle Area (AMA) (-0.351**), Arm Fat Area (AFA) $\left(0.215^{*}\right)$. Health conditions like diabetes, hypertension, heart disease, arthritis and gout were positively associated with nutrient intake such as energy, carbohydrate and fat. These health conditions were also positively and significantly associated with anthropometric parameters viz. BMI $\left(0.853^{*}\right)$, WHR (0.219*), WHtR (0.192*), Percent Body Fat (PBF) and Fat Mass (FM) (0.199*).
\end{abstract}

[*Significant at $p<0.05, * *$ Significant at $p<0.01]$

Keywords: diabetes, hypertension, correlation, parameters

\section{INTRODUCTION}

India is passing through a demographic transition commonly called 'Pyramid to Pillar'. This means that number of elderly persons is increasing at a much faster pace as compare to the general population - a structure which was earlier regarded as a pyramid now shapen as a pillar. Increase in life expectancy, substantial progress in health care amenities and demographic transition has brought about a fast aging of world population. As per 2011 census, total population of 60 plus was 103.6 million and which were projected to rise to nearly 12 crore by 2016 and 14 crore by 2021 in India.

Geriatric nutrition deals with the health of an individual above 60 years of age. In the area of geriatrics, there is a triad, Nutrition-Health-Aging, which cannot be separated and are parts of an integral whole. Geriatric nutrition also applies nutrition principles to delay effects of aging and disease; to aid in the management of the physical, psychological, and psycho-social changes commonly associated with advancing age. With the increasing age, there are certain metabolic changes and also reduction in physical activities and as a result energy requirement in elderly is substantially reduced than younger adults. As an individual grows older, a number of changes occur in the body which affect the nutrient needs, dietary intake and the nutrient utilization and thus, have a bearing on the overall nutritional status. As adequate nutrition and a well-balanced diet are of vital importance even during old age so as to prevent and control the community hazard of aging.

Keeping the significance in view there is an urgent need to give due care to this vulnerable strata of our society. So, the proposed study was subcategorized among the actively working and retired geriatrics to see the impact of activity on their nutritional as well as health status.

\section{Materials ANd Methods}

\section{Sampling procedure:}

The present studywas conducted by collecting suitable representative sample of 120 elderly from two blocks viz. Panchrukhi and Baijnath representing District Kangra. The selected geriatric subjects were 
further sub-categorized into two groups i.e. retired (which were retired and above 60 years of age) and active working (which were doing business or involved in any other kind of occupation after the age of 60 years).

\section{Collection of data:}

Data was collected through personal interview method along with rapport formation with the subject to get authenticated information as far as possible. Indirect queries were also made to help to ascertain correct information. In order to meet the objectives of the study, the data was collected through a well-structured questionnaire cum interview schedule which was divided in various categories viz.

\section{Anthropometry}

To assess the impact of nutrition on health status, it was attempted to check the anthropometry measurements of the respondents. Because anthropometric measurements give the indication of past as well as present nutritional status which overall reflect the health status.

Height (Ht): The height was measured with the help of anthropometric $\operatorname{rod}^{[1]}$.

Weight (Wt): The weights of the respondents were taken using the weighing balance calibrated in kilograms and grams ${ }^{[1]}$. The body weight was determined to the nearest of $0.5 \mathrm{~kg}$ to avoid errors using weighing machine.

Mid-Upper Arm Circumference (MUAC): The measurements were taken firmly around mid way marked the lateral part of the left upper arm with the subjects forearm held in horizontal position.

Body Mass Index (BMI): The index was calculated for each of the subject as weight $(\mathrm{kg})$ divided by height $\left(\mathrm{m}^{2}\right)^{[2]}$.

$$
\begin{aligned}
& \text { Weight }(\mathrm{kg}) \\
& \mathrm{BMI}= \\
& \text { Height }\left(\mathrm{m}^{2}\right)
\end{aligned}
$$

\begin{tabular}{|c|c|c|}
\hline$\underline{\text { Classification }}$ & $\underline{\mathrm{BMI} \mathrm{kg} / \mathrm{m}^{2}}$ & $\underline{\text { Risk of co-morbidities }}$ \\
\hline Underweight & $\leq 18.50$ & $\begin{array}{l}\text { Low (but risk of other clinical } \\
\text { problems increased) }\end{array}$ \\
\hline Normal range & $18.50-24.99$ & Average \\
\hline Overweight & $\geq 25.00$ & Increased \\
\hline Pre-obese & $25.00-29.99$ & Increased \\
\hline Obese class-I & $30.00-34.99$ & Moderate \\
\hline Obese class-II & $35.00-39.99$ & Severe \\
\hline Obese class-III & $\geq 40.00$ & Very severe \\
\hline
\end{tabular}

Interpretation - BMI was compared with the following classification ${ }^{[3]}$.

Waist and Hip Circumference (WHC): Waist and Hip circumference is a measurement at the level of navel, when the subject breathes quietly whereas, hip circumference was measured at the intertichantric level ${ }^{[4]}$ with the help of non-stretchable tape.

Waist to Hip Ratio (WHR): WHR is an indicator of abdominal obesity. It was calculated by the formula given as ${ }^{[5]}$ :

$$
\text { Waist circumference }(\mathrm{cm})
$$

Waist to Hip ratio $=$

Hip circumference $(\mathrm{cm})$ 


\section{Classification used:}

$\begin{array}{cc}\text { Sex } & \text { Normal Range for WHR } \\ \text { Male } & \geq 0.95 \\ \text { Female } & \geq 0.80\end{array}$

Waist to Height Ratio (WHtR): Waist circumference is improved by relating it to height to categorized fat distribution and WHtR is a simple and practical anthropometric index to identify higher metabolic risks in normal and overweight people ${ }^{[6]}$.

\section{Classification used:}
Range
Interpretation
$<0.50$
Considered Normal
$\geq 0.60$
Considered boundary value for CVD risks

Skin fold thickness: The Harpenden Skinfold Calliper was used to measure skinfold thickness such as Triceps, Biceps, Subscapular and Suprailliac to the nearest of $0.1 \mathrm{~mm}^{[1]}$.

Per cent Body Fat (PBF): It was calculated from the sum of Tricep, Biceps, Subscapular and Suprailliac from equation given as ${ }^{[7]}$ :

Body density $=1.1599-(0.0717 * \log$ of sum of all four skin fold $)$.

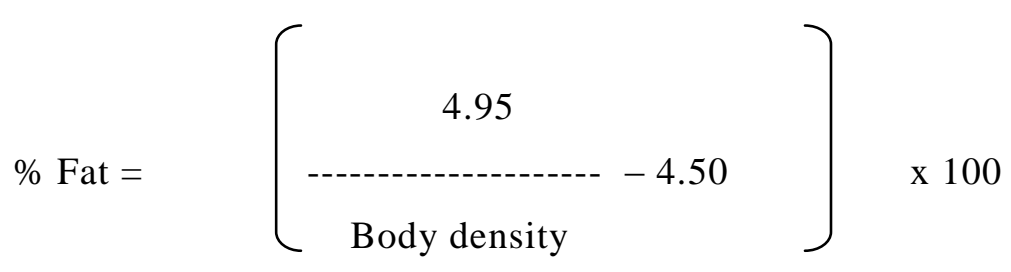

\section{Interpretation}

The values thus obtained were interpreted as per the classification of Per cent Body Fat suggested as follow ${ }^{[8]}$ :

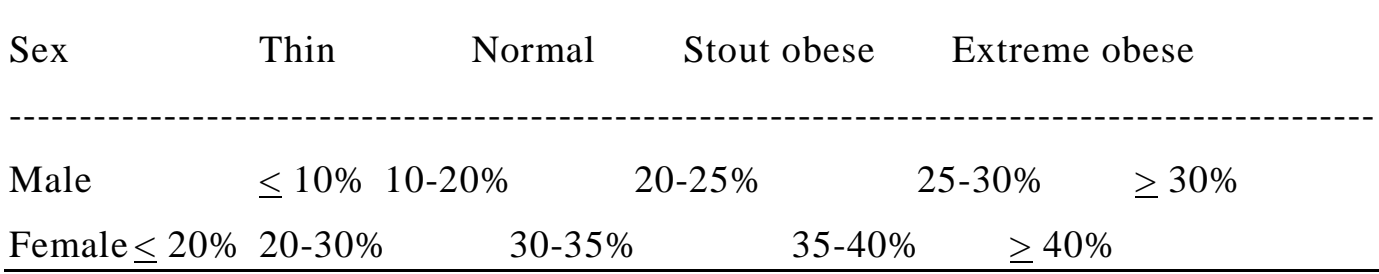

Arm Muscle Circumference (AMC): Arm muscle circumference is calculated by the equation given as ${ }^{[9]}$ :

$\operatorname{AMC}(\mathrm{cm})=\operatorname{MUAC}(\mathrm{cm})-22 / 7 \mathrm{x}($ Triceps skin fold in $\mathrm{cm})$

Arm Muscle Area (AMA): Arm Muscle Area is calculated by the formula given as ${ }^{[10]}$ :

$$
\operatorname{AMA}\left(\mathrm{cm}^{2}\right)=(\mathrm{AMC})^{2} / 4 \times 22 / 7
$$

Arm Fat Area (AFA): Arm Fat Area is calculated by the equation given as ${ }^{[10]}$ :

$$
\operatorname{AFA}(\mathrm{cm})^{2}=1 / 4 \times(22 / 7)\left((\mathrm{MUAC})^{2}-(\mathrm{AMC})^{2}\right)
$$

Fat Mass (FM): Fat Mass is calculated as

$\mathrm{FM}(\mathrm{kg})=(\mathrm{PBF} / 100) \mathrm{x}$ Weight $(\mathrm{kg})(\mathrm{PBF}$ mention from section $\mathrm{i}$ of anthropometry $)$

Fat Free Mass (FFM): Fat Free Mass is calculated as

FFM $(\mathrm{kg})=$ Weight $(\mathrm{kg})-$ FM $(\mathrm{kg})$ 
Correlation of nutrient intake with anthropometry parameters, nutrient intake with health status, anthropometry parameters with health status and correlation of health status with age \& physical activity was assessed.

\section{RESUlT AND DISCUSSION}

\section{Correlation between Nutrition and Health}

\section{Correlation of Health with Nutrients}

\section{Diabetes}

The data regarding relationship between nutrient and health is shown in Table 1. Amongst the surveyed subjects 32.5 per cent were found obese (Grade I and II) and 9.17 were diabetic. Data reveals that diabetes has a positive correlation with all the nutritional parameters except for fiber, fiber had a negative significant association with diabetes, as it reduces dietary glycemic index, thus maintaining a high fiber intake may reduce the risk of Type 2 diabetes. One reason might that fiber slows down the digestion of carbohydrates, leading to a less severe spike in after-meal blood glucose level. Energy also had a positive as well as significant $(\mathrm{p}<0.05)$ correlation $(\mathrm{r}=0.218)$ with diabetes. As higher energy intake increased the body weight which built pressure on pancreas and affect insulin secretion with the result, body is not able to control blood sugar level ultimately resulted into hyperglycemia and one more reason is that increased body weight alter the body's response to insulin, potentially leading to insulin resistance.

Intake of total and saturated fats were associated with a higher risk of Type 2 diabetes ${ }^{[11]}$. Excessive intake of energy can elevate the blood sugar level and increases the chance of Type 2 Diabetes ${ }^{[12]}$. These studies are in concordance with present findings.

Table 1. Correlation of Health with Nutritional parameters

\begin{tabular}{|l|c|c|c|c|c|c|c|}
\hline & Energy & Carbohydrate & Protein & Fat & Calcium & Iron & Fiber \\
\hline Diabetes & $0.218^{*}$ & 0.014 & 0.142 & 0.132 & 0.042 & 0.108 & $-0.228^{*}$ \\
\hline Hypertension & $0.497^{*}$ & 0.056 & 0.039 & $0.203 *$ & -0.094 & -0.050 & -0.168 \\
\hline Heart disease & $0.227 *$ & 0.003 & $-0.189 *$ & 0.071 & -0.063 & -0.031 & $-0.289^{*}$ \\
\hline Arthritis & 0.066 & 0.025 & -0.045 & 0.001 & -0.059 & -0.021 & 0.018 \\
\hline Gout & 0.128 & 0.053 & 0.115 & 0.001 & 0.019 & 0.055 & 0.007 \\
\hline
\end{tabular}

\section{Hypertension and Heart Disease}

From the same Table it was observed that hypertension and heart diseases were significantly and positively associated with energy and total fat consumption. However, calcium and fiber intake is negatively associated with hypertension and heart disease. Fiber is associated with lowered cholesterol level. Fiber also creates a feeling of fullness or satiety, helping to curb appetite and leading to less overeating and results in weight control. Consumption of higher amount of energy than the body's requirement was stored in the body but if it took place for a prolonged period it ultimately converted into fat and leads to obesity. An obese person has more body mass due to having more body fat. This increased mass means the person has more blood flowing that is being pumped by the heart throughout the body. Therefore, the heart must work harder to pump blood throughout the body, which causes strain on the heart. This strain is often doubled when the obese person exerts himself and experiences a higher heart rate, as the blood flowing through the heart is too much for the heart to handle and increases the chances of coronary heart diseases. Among geriatric subjects consumption of saturated fats like full cream milk, butter, desi ghee, meat etc. is one of the main reason for developing cardiac disease. Iron intake is negatively correlated with heart disease; it might be due to the fact that anaemia was effective in elevating oxidative stress which leads to the development of various degenerative diseases like cardiovascular risk. Therefore, iron deficiency as well as iron overload could increase oxidative stress possibly involved in the occurrence of hypertension.

Systolic blood pressure was positively associated with protein intake $(\mathrm{P}<0.05)^{[13]}$. Low non-heme iron intake at baseline was associated with a greater increase in systolic blood pressure (SBP) ${ }^{[14]}$. People who do not get enough calcium may be at higher risk for hypertension and some studies suggest that increasing calcium levels may lower blood pressure slightly. Total visible fat ( $>20 \mathrm{~g} /$ day) intake was 
Studies to See the Effect of Nutrition on the Health Status of Selected Retired and Active Working Elderly People

positively associated, whereas fruit, vegetable, legume and coconut intake ( $<400 \mathrm{~g} / \mathrm{day})$ was inversely associated with hypertension ${ }^{[15]}$. These findings are in agreement with present study.

\section{Arthritis and Gout}

Arthritis had a negative correlation with protein, calcium and iron while gout was positively correlated with all nutrients, however correlation was non-significant. Adequate calcium intake is important because the body loses calcium every day through the skin, nails, hair, and sweat, as well as through urine and feces. This lost calcium must be replaced daily through the diet. Otherwise, the body takes calcium from the bones to perform other functions, which makes the bones weaker and more likely to break over time. Depletion of body calcium and inadequate absorption of calcium and vitamin $\mathrm{D}$ in old age is also one of the main reasons for the occurrence of arthritis. Adequate dietary calcium intake and maintaining a physically active lifestyle in late decades of life could potentially translate into a reduction in the risk of osteoporosis and hence improve the quality and perhaps quantity of life in the elderly population.

\section{Correlation between Health and Anthropometric parameters}

\section{Diabetes}

As is evident from the Table 2 Diabetes have a significant $(\mathrm{p}<0.05)$ and positive correlation with BMI $(\mathrm{r}=0.853)$ and Waist to Height Ratio (WHtR) $(\mathrm{r}=0.207)$. Diabetes was also found positively correlated with WHR $(r=0.020)$, PBF $(r=0.063)$, AMC $(r=0.115)$, AMA $(r=0.126)$, AFA $(r=$ $0.133), F M(r=0.029)$ and FFM $(r=-0.050)$. Increased body fat is generally associated with an increase in the risk of metabolic diseases such as Type 2 Diabetes mellitus, hypertension and dyslipidemia. In addition, majority of the geriatric subjects with these metabolic diseases are either overweight or obese. Type 2 diabetes is associated with insulin resistance. Insulin, which is an important hormone that delivers glucose (sugar) to our cells. When a person is overweight, the cells in the body become less sensitive to the insulin that is released from the $\beta$ cells of pancreas. There is some evidence that fat cells are more resistant to insulin than muscle cells. If a person has more fat cells than muscle cells, then the insulin becomes less effective overall and glucose remains circulating in the blood instead of being taken in to the cells to be used as energy and resulted into hyperglycemia.

Table 2. Correlation between Health and Anthropometric parameters

\begin{tabular}{|l|c|c|c|c|c|}
\hline $\begin{array}{c}\text { Metabolic Disorder } \\
\text { Anthropometry } \\
\text { Parameter }\end{array}$ & Diabetes & Hypertension & $\begin{array}{c}\text { Heart } \\
\text { Disease }\end{array}$ & Arthritis & Gout \\
\hline Body Mass Index (BMI) & $0.853^{*}$ & $0.398^{* *}$ & $0.211^{*}$ & 0.006 & 0.042 \\
\hline Waist to Hip Ratio (WHR) & 0.020 & $0.219^{*}$ & $0.180^{*}$ & 0.019 & 0.107 \\
\hline Waist to Height Ratio (WHtR) & $0.207^{*}$ & $0.192^{*}$ & $0.217^{*}$ & 0.014 & 0.008 \\
\hline Per cent Body Fat (PBF) & 0.063 & 0.032 & 0.145 & 0.036 & 0.043 \\
\hline $\begin{array}{l}\text { Arm Muscle Circumference } \\
\text { (AMC) }\end{array}$ & 0.115 & 0.127 & $0.210^{*}$ & 0.026 & 0.073 \\
\hline Arm Muscle Area (AMA) & 0.126 & -0.020 & 0.115 & 0.024 & 0.060 \\
\hline Arm Fat Area (AFA) & 0.133 & -0.056 & 0.051 & 0.007 & 0.028 \\
\hline Fat Mass (FM) & 0.029 & 0.019 & $0.199 *$ & 0.007 & 0.035 \\
\hline Fat Free Mass (FFM) & -0.050 & -0.036 & 0.038 & 0.116 & 0.006 \\
\hline \multicolumn{2}{|r|}{ *Significant at p<0.05 } & $* *$ Significant at p<0.01 & &
\end{tabular}

Pooled relative risks for incident of Diabetes were associated with Body Mass index, Waist Circumference and Waist/Hip ratio, respectively ${ }^{[16]}$. This gives credence to the present work. Diabetes mellitus with special reference to Body Fat Percentage and found that BMI was four times higher in diabetic subjects than control groups $(95 \% \mathrm{CI}-2.49-7.20, \mathrm{p}<0.001)^{[17]}$.

Responsible factors for the complications among geriatric group such as diets, physical activities as well as work and functional status are of more of concerns and should be included in further studies.

\section{Hypertension}

Hypertension was found highly significant $(\mathrm{p}<0.01)$ and positively correlated $(\mathrm{r}=0.398)$ with BMI. It was also found significant $(\mathrm{p}<0.05)$ and positively correlated with WHR $(\mathrm{r}=0.219)$ and WHtR $(\mathrm{r}=$ 
0.192). Hypertension was also found positively correlated with PBF, AMC and FM, however correlation was non-significant. High blood pressure is twice as common in adults who are obese than in those who are at a healthy weight. Obesity is regarded as the chronic inflammation by adipocytesecreted agents and this may account for the development of the metabolic syndrome. In other words, pro-inflammatory cytokines, specific hormones and free fatty acids that are secreted by adipose tissue resulted into hypertension by affecting the renin-angiotensin aldosterone system. These agents also affect dyslipidemia and insulin resistance.

Correlations of Body Mass Index, Waist to Hip ratio and Skin fold measurements with diastolic hypertension varied with age and sex ${ }^{[18]}$. BMI, WHR and WHtR were highly significant and positively correlated with diastolic blood pressure in hypertensive men ${ }^{[19]}$. Increased BMI was associated with increased prevalence of hypertension and diabetes ${ }^{[20]}$. A statistically significant positive correlations was found between indices of adiposity (BMI and WHR) and blood pressure $(p<0.01)^{[21]}$. These results are in line with present findings.

\section{Heart disease}

Heart disease was found significantly and positively correlated with BMI $(r=0.211)$, WHR $(r=$ $0.180)$, WHtR $(r=0.217)$, FFM $(r=0.199)$ and AMC $(r=0.210)$. While rest of anthropometric parameters viz. PBF, AMA, AFA and FFM were found positively correlated but correlation was nonsignificant. High waist to hip ratio had increased risk of death stroke, ischemic heart disease, diabetes, hypertension and hyperlipidemia.

Obesity is associated with high triglycerides and decreased HDL cholesterol. Cholesterol, a fat-like substance carried in blood stream, is found in all of the body's cells. Liver produces all of the cholesterol as body needs to form cell membranes and to make certain hormones. Extra cholesterol enters the body with the excess consumption of animal foods (meats, eggs and dairy products) which are rich in cholesterol and low in fiber. Although the excessive consumption of saturated fats like fat in milk products, fat from red meat and tropical oils such as coconut oil is the main culprit for the elevation of blood cholesterol level. Too much low-density lipoprotein (LDL or "bad cholesterol") in the blood causes plaque to form on artery walls, leading to atherosclerosis. When plaque builds up in the coronary arteries that supply blood to the heart, then the risk of having a heart attack increases. Increased Waist Circumference was associated with dyslipidemia, hypertension and abnormal serum glucose, whereas an increased Body Mass Index was only associated with dyslipidemia.

All these risk factors responsible for cardiovascular disease, reduced high density lipoprotein cholesterol leveland hypertension were those more strongly associated with higherBMI in both men and women ${ }^{[22]}$. There was a strong relationship between body fat distribution and cardiovascular diseases ${ }^{[23]}$. The present work is in line with studies done earlier by different investigators.

\section{Arthritis and Gout}

Arthritis and gout has a positive but non-significant correlation with all the anthropometric parameters. Presumably, excess adipose tissue on weight bearing joints would be more burdensome on the weaker bones of geriatric group. Furthermore, a decrease in sex hormones (such as estrogen) in female elderly might lead to a weakening of their bone density. Results are in same line as observed by and confirm that BMI and weight are strongly associated with radiographic knee osteoarthritis in women ${ }^{[24]}$. BMI is an independent risk factor for self-reported arthritis. Maintaining a healthy weight may delay the onset of arthritis ${ }^{[25]}$.

Obese people often have hyperuricemia, which frequently leads to painful attacks of gout. It has been suggested that increased serum uric acid and gout occurrence are closely associated with an increase in visceral fat accumulation. Higher adiposity and weight gain are strong risk factors for gout ${ }^{[26]}$.

Most of these recent studies continue to show that increased level of obesity is associated with greater risks of coronary artery disease (as well as an increasing incidence of high blood pressure, diabetes, stroke, arthritis, some forms of cancer and premature death). This gives credence to the present work.

\section{Correlation of Health with Physical activity and Age}

Data regarding the correlation between health, physical activity and age represented in Table 3 and observed that all health problems are negativelycorrelated with physical activity. 
Studies to See the Effect of Nutrition on the Health Status of Selected Retired and Active Working Elderly People

Table 3. Correlation among Health, Physical activity and Age.

\begin{tabular}{|l|c|c|c|}
\hline & Physical activity & Exercise & Age \\
\hline Diabetes & -0.033 & $-0.234^{*}$ & 0.008 \\
\hline Hypertension & $-0.181^{*}$ & $-0.298^{* *}$ & $0.211^{*}$ \\
\hline Heart disease & -0.153 & $-0.182^{*}$ & $0.215^{*}$ \\
\hline Arthritis & -0.070 & -0.011 & 0.058 \\
\hline Gout & $-0.243^{*}$ & -0.060 & 0.169 \\
\hline \multicolumn{2}{|c|}{$* *$ Significant at $\mathrm{p}<0.01$}
\end{tabular}

Gout and Arthritis

Gout have highly significant $(\mathrm{p}<0.01)$ and negative correlation $(\mathrm{r}=0.243)$ with physical activity. Arthritis was also negatively correlated with both physical activity and exercise. Exercises put a lot of strain on muscles and bones and strengthen them. For both sexes, bone calcium content is improved with exercise and the risk of osteoarthritis and fractures also goes down. Regular weight-bearing exercise promotes bone formation and may prevent many forms of bone loss associated with aging.

\section{Hypertension}

Exercise was highly significantly $(\mathrm{p}<0.01)$ and negatively correlated $(\mathrm{r}=-0.298)$ with hypertension. Regular physical activity can reduce blood pressure in those with high blood pressure level. Physical activity also reduces body fatness, which is associated with high blood pressure.

\section{Heart disease and Diabetes}

Heart disease and Diabetes also have a significant $(\mathrm{p}<0.05)$ and negative correlation with exercise. Daily physical activity can help to prevent heart disease and stroke by strengthening heart muscles, lowering blood pressure, raising high-density lipoprotein (HDL) level (good cholesterol) and lowering low-density lipoprotein (LDL) level (bad cholesterol), improving blood flow and increasing heart's working capacity. By reducing body fatness, physical activity can help to prevent and control Type 2 diabetes. Age has positive correlation with all the health problems, however only hypertension and heart disease were significantly $(\mathrm{p}<0.05)$ associated. Physical exercise lowers LDL cholesterol (the bad cholesterol) as well as triglycerides in blood. Increased amount of blood fat especially in the form of triglycerides associated with a higher risk of heart disease. Exercise also burn extra calories which was not used by body to perform all its activity which decreases the chances of health problems such as diabetes, heart disease etc. with increasing age chances of developing diseases also increase as body lose its immunity to fight against infections and immobility is one of the main cause for developing metabolic syndromes. Preventive resources among the elderly should include moderate exercise such as walking.

Physical activity, even occasionally, decreases the risk of all-cause mortality among elderly people ${ }^{[27]}$. This study was in agreement with present findings.

\section{Correlation of Age and Nutrient intake with Anthropometric parameters}

Age

Table 4. Correlation between Age and Nutrient intake with Anthropometric parameters

\begin{tabular}{|l|c|c|c|c|c|c|c|c|c|}
\hline & BMI & WHR & WHtR & PBF & AMC & AMA & AFA & FM & FFM \\
\hline Age & - & $0.291 * *$ & 0.143 & -0.074 & - & - & $0.215^{*}$ & -0.033 & -0.083 \\
& $0.343 * *$ & & & & $0.284 * *$ & $0.351 * *$ & & & \\
\hline Energy & 0.065 & 0.130 & 0.102 & 0.023 & 0.130 & 0.102 & 0.055 & 0.011 & 0.001 \\
\hline Carbohydrate & 0.008 & 0.008 & 0.147 & 0.026 & 0.063 & 0.050 & 0.058 & 0.030 & 0.110 \\
\hline Protein & -0.047 & 0.081 & 0.034 & - & -0.015 & -0.016 & -0.030 & 0.163 & 0.072 \\
& & & & $0.193 *$ & & & & & \\
\hline Fat & 0.021 & 0.174 & $0.262 * *$ & 0.085 & 0.147 & 0.151 & $0.187 *$ & 0.048 & 0.072 \\
\hline
\end{tabular}

Table 4 represents the data regarding correlation of age and nutrient intake with body measurements. Age has a negative $(r=-0.343)$ and highly significant $(\mathrm{p}<0.01)$ correlation with BMI. With advancing age BMI increases up to 70 years and after that it become constant and start decreasing due to the loss of weight and body also start losing muscle mass due to aging process resulting loss in weight and 
almost all the anthropometric indices. Loss of appetite is also a part of aging process. Age of geriatric subjects also positively and significantly correlated with WHR, FFM and AFA. Per cent body fat and fat mass also had a inverse age trend which mean that as age advanced there is a loss of subcutaneous fat due to the age related loss of collagen fiber which provide matrix to adipocytes of adipose tissue ${ }^{[28]}$ and the results are in accordance with present study.

It was of utmost importance to study the factors involved in the causation of this negative trend that could have serious health implications particularly in clinical nutrition and serious heath complications associated with increasing age.

\section{Energy and Carbohydrate}

Energy and carbohydrate were positively but non-significantly correlated with all the anthropometric parameters. Increased energy intake as compared to the need of the body aid in increase in body weight and cause obesity and higher anthropometric parameters. Protein was negatively associated with BMI, PBF, AMC, AMA and AFA while positively correlated with WHR, WHtR, FM and FFM. Protein from animal sources contain more of saturated fat and lead to deposition among body and ultimately aid in higher anthropometric values for different parameters. Fat was positively associated with all the anthropometric parameters and highly significantly $(\mathrm{p}<0.01)$ correlated $(\mathrm{r}=0.262)$ with WHtR. Excess of consumption of fat lead to obesity or weight gain and ultimately resulted in metabolic syndrome. During old age there is more accumulation of adipose tissues among the abdominal region which aid in central obesity and results in higher value for predictors of abdominal obesity like WHR and WHtR.

\section{Conclusion}

From the aforesaid discussion it is inferred that nutrition plays a very important role on the health status of an individual especially geriatric group. The most vulnerable segment of our society, reflects long term nutrition through the anthropometric measurements. If one does not take care of diet during early stages of life it may lead to many of health problems in the later hood.

\section{ACKNOWLEDGEMENT}

One of the author acknowledge financial assistance from university authorities for providing in the form of merit scholarship during the study period and also indebted to the selected greying chunk of the society without their corporation it would not be possible.

\section{REFERENCES}

[1] Jelliffe DB. The assessment of the nutritional status of the community. World Health Organisation Monograph Series 53, Geneva: 50-84(1966).

[2] Garow JC. Treat obesity seriously. A clinical Manual. Edinburgh Churchill, Liviingstone. Publishing, U.K. :347-355(1981).

[3] World Health Organization. Obesity: Preventing and managing the Global Epidemic: Report of WHO consultation on obesity. Geneva: WHO. p 9(1998).

[4] Despres JP. Obesity and lipid metabolism relevance of body fat distribution. Current Opinion in Lipidology 2, 5-15(1991).

[5] Florencio TT, Ferreira HS, Cavalcante JC et al. Short staure, obesity and arterial hypertension in a very low income population in North Eastern Brazil. Nutrition, Metabolism and Cardiovascular Diseases 14, 26-33(2004).

[6] Hseih SD, Yoshinaga $\mathrm{H}$ and Muto T. Waist to height ratio, a simple and practical index for assessing central fat distribution and metabolic risk in Japnese men and women. International Journal of obesity related Metabolic Disorders 27, 610-616(2003).

[7] Durnin JVGA and Womersley J. Body fat assessed from total body density and its estimation from skinfold thickness measurements on 481 men and women aged from 16 to 72 years. British Journal of Nutrition 3, 77-94(1977).

[8] Deurenberg P, Pieters JJL and Hautvast JGA. The assessment of the body fat percentage by skinfold thickness measurements in childhood and young adolescence. British Journal of Nutrition 63, 293-303(1998). 
Studies to See the Effect of Nutrition on the Health Status of Selected Retired and Active Working Elderly People

[9] Linder MC. Nutritional Biochemistry and Metabolism with clinical applications. Elsevier Science Publishing Company. New York(1985).

[10] Frisancho AR. New norms of upper limb fat and muscle areas for assessment of nutritional status. American Journal of Clinical Nutrition 34, 2540-2545(1981).

[11] Dam RMV, Willett CW, Rimm BM et al. Dietary Fat and Meat Intake in Relation to Risk of Type 2 Diabetes in Men. Diabetic Care 25, 417-424(2002).

[12] Tyrovolas S, Zeimbekis A, Bountziouka V et al. Factors Associated with the Prevalence of Diabetes Mellitus Among Elderly Men and Women Living in Mediterranean Islands. Review of Diabetic Studies 6, 54-63(2009).

[13] Hajjar IM, Grim CE, George V et al. Impact of diet on blood pressure and age-related changes in blood pressure in the US population. Archives of Internal Medicine 161, 589-593(2001).

[14] Galan P, Vergnaud AC, Tzoulaki I et al. Low Total and Nonheme Iron Intakes Are Associated with a Greater Risk of Hypertension. The Journal of Nutrition 140, 75-80(2010)

[15] Beegom R and Singh RB. Association of higher saturated fat intake with higher risk of hypertension in an urban population of Trivandrum in South India. American Journal of Clinical Nutrition 54, 136-40(1991).

[16] Vazquezt G, Duval S, Jacobs DR et al. Comparison of Body Mass Index, Waist Circumference, and Waist/Hip Ratio in Predicting Incident Diabetes: A Meta-Analysis. Epidemiological Review 29, 115-128(2007).

[17] Mahanta BN and Mahanta TG. Clinical Profile of Persons with Family History of Diabetes Mellitus with Special Reference to Body Fat Percentage. Journal of Association of Physicians of India 57, 641-643(2009).

[18] White FMM, Pereira LH and Garner JB. Associations of body mass index and waist:hip ratio with hypertension. Canadian Medical Association Journal 35, 313-320(1986).

[19] Sonika. 2007. Nutritional status of selected hypertensive subjects from Palampur region of Kangra District. M.Sc. Thesis. Department of Food Science and Nutrition, CSK Himachal Pradesh KrishiVishvavidyalayaPalampur, India.

[20] Bays HS, Chapman RH and Grandy S. The Relationship of Body Mass Index to Diabetes Mellitus, Hypertension and Dyslipidaemia: Comparison of Data from Two National Surveys. International Journal of Clinical Practice 61, 737-747(2007).

[21] Tyagi R and Kapoor S. Functional ability and nutritional status of Indian elderly. The Open Anthropology Journal 20, 200-205(2010).

[22] Fava SL, Peter Wilson PWF and Schaefer JE. Impact of Body Mass Index on Coronary Heart Disease Risk Factors in Men and Women. Arteriosclerosis, Thrombosis and Vascular Biology 16, 1509-1515(1996).

[23] Kato MM, Currier MB, Villaverde $\mathrm{O}$ et al. The relation between body fat distribution and cardiovascular risk factors in patients with Schizophrenia: A cross-sectional pilot study. Journal of Clinical Psychiatry 7, 115-118(2005).

[24] Abbate LM, Stevens J, Schwartz TA et al. Anthropometric measures, body composition, body fat distribution, and knee osteoarthritis in women. Obesity 14, 1274-1281(2006).

[25] Zakkak JM, Wilson DB and Lanier JO. The Association Between Body Mass Index and Arthritis Among US Adults: CDC's Surveillance Case Definition. Preventive Chronic Diseases 6, 111(2009).

[26] Choi HK, Atkinson K, Karlson WE et al.Obesity, Weight Change, Hypertension, Diuretic Use, and Risk of Gout in Men. Archives of International Medicine 165, 742-748(2005).

[27] Sundquist K, Qvist J, Sundquist J et al.. Frequent and occasional physical activity in the elderly: A 12 year follow up study of mortality. American Journal of Preventive Medicine 27, 2227(2004)

[28] Guyton AC and Hali JE. Text book of medical physiology. Prism Books, Banglore, India (1996). 